\title{
REVIEW
}

\section{Overview of ARIES nuclear assessments: neutronics, shielding, and activation}

\author{
Laila El-Guebaly* and the ARIES Team
}

University of Wisconsin, 1500 Engineering Dr., Madison, WI 53706, USA

\begin{abstract}
Power plant projects, like ARIES, present an essential element of the US fusion developmental process in order to provide a perspective on potential fusion concepts and understand future trends. The nuclear assessment has been a fundamental element of the ARIES project since its inception in the early 1990s. Over the years, we performed state-of-the-art assessments to understand the rational basis for the damaging/enhancing changes to the tritium breeding of several design elements. Equally important, we developed a new scheme to control the tritium breeding online, novel approaches to deliver well-optimized shields for various fusion concepts, and a new strategy to handle the continuous stream of radioactive materials and minimize the radwaste burden for future generations. The collective impact of such innovations has done much to shape the design development of the various ARIES concepts over the past 20 years.
\end{abstract}

\section{Keywords: ARIES project; fusion power plants; tritium breeding ratio; neutronics; shielding; activation;} radwaste management; recycling; clearance

\section{Introduction}

The ARIES project [1] is a national, multi-institutional research activity, performing advanced integrated design studies to identify key R\&D directions and provide visions for the US fusion program. The project delivered numerous design studies that looked to the future and envisioned the far end of the fusion power development path past ITER and past a demonstration plant, to the tenth of its kind fusion power plant. These studies highlight emerging physics and technology challenges, and present a perspective on potential fusion concepts, such as tokamak, stellarator, spherical torus, etc. The timeline for the ARIES designs is displayed in Figure 1. Most of the effort has been focused on tokamaks, spanning a wide range of advanced and conventional physics and technologies

The nuclear assessment received considerable attention during the ARIES studies, encompassing three closely related tasks: neutronics, shielding, and activation. Performing this assessment, an integral approach that considers the overall configuration, design requirements, low-activation materials choice, and component optimization was deemed necessary to deliver optimal ARIES power plants. As discussed in Section 2, the ability of the blanket to provide tritium self-sufficiency is among the most important issues investigated in detail with sophisticated neutronics analyses to pinpoint the design elements that degrade the breeding the most - an issue that puzzled the fusion community for decades.

*Corresponding author. Email: elguebaly@engr.wisc.edu

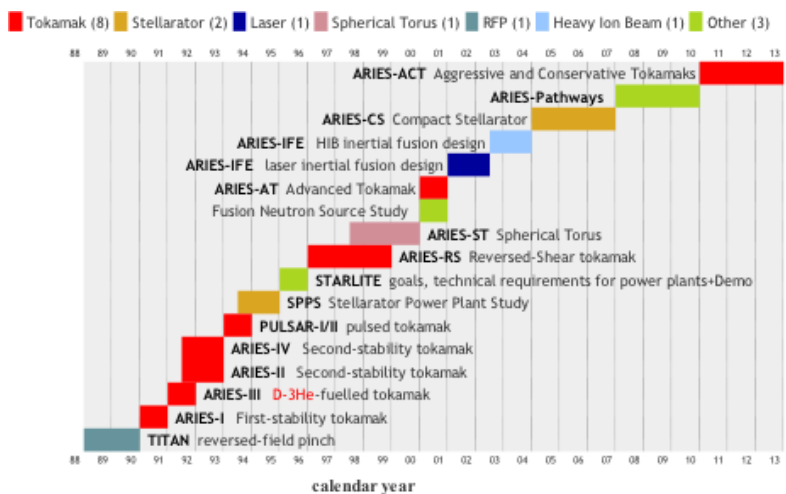

Figure 1. Timeline of ARIES studies.

Each design concept has a unique shielding feature. All specialized components (blanket, structural ring, manifolds, vacuum vessel, etc.) should provide a shielding function to collectively satisfy radiation protection requirements with minimum radial standoffs. Section 3 highlights examples of well-optimized shielding schemes for selected tokamak, stellarator, and spherical torus power plants.

Proper handling of fusion radioactive materials is important to the future of fusion energy. Besides the need to avoid the generation of high-level waste, fusion should establish a more integral strategy to handle the sizable radwaste and to deal with the more restrictive future regulatory environment for disposal of radioactive materials. Section 4 outlines environmental benefits of recycling (reuse within the nuclear industry) and clearance (release to the commercial market, if materials contain traces of radioactivity). 


\section{The tritium breeding issue and reality}

Recent advances in computational techniques enabled computing the tritium breeding ratio (TBR) with higher fidelity than was previously possible. We addressed many breeding-related questions and concerns within the framework of the most recent ARIES-ACT study [1]. The availability of the state-of-the-art 3-D neutronics code (DAGMC [2]) facilitated fully accurate modeling of complex devices by integrating the computer-aided design (CAD) geometry directly with the 3-D MCNP code [3]. Even though this tool has overcome a major limitation in the TBR analysis, several questions remained unanswered: How does the blanket structure (first wall, side and back walls, cooling channels, etc.) degrade the breeding? Which change to the blanket dimension, composition, and/or Li enrichment is more enhancing to the breeding? How does the advanced physics (that requires embedding stabilizing shells within the blanket) degrade the breeding? Could the required TBR be achieved in the presence of several plasma heating and current drive ports that compete for the best available space for breeding? Past studies made several attempts to answer some questions by addressing individual issues - one at a time. However, there are still some concerns regarding the inter-dependence and synergistic impact of the various design elements on TBR and the degree of confidence in the single-effect analysis. To address these concerns, we recently developed a novel stepwise approach to identify the exact cause of the degradation in TBR and examine almost all questions collectively in an integral fashion. This new approach was first applied to an interim ARIES-ACT design [4] to address the questions and concerns mentioned above. Here, we reapplied the stepwise approach to the near-final ARIES-ACT design to confirm that the most recent modifications made to the top/bottom ends of the outboard dual-cooled lithium-lead (DCLL) blanket comply with the ARIES breeding requirements (overall TBR of 1.05 with ${ }^{6} \mathrm{Li}$ enrichment $<90 \%$ ).

Figure 2 shows the end results for the TBR assessment for the $\mathrm{LiPb}$ breeder with 15.7 at\% $\mathrm{Li}$ and 84.3 at $\% \mathrm{~Pb}$. This bar chart represents the calculated TBR from a series of ten 3-D runs performed to illustrate the stepwise degradation in breeding by various elements of blanket internals and surroundings. The first step provides the highest achievable TBR for $\mathrm{LiPb}$ breeder with $90 \%{ }^{6} \mathrm{Li}$ enrichment. In the $2^{\text {nd }}$ step, the toroidal model was constructed with $0.45 \mathrm{~m}$ inboard (IB) and $1 \mathrm{~m}$ outboard (OB) breeding zones surrounded with the shield and divertor. The 3-D configuration with such a limited radial thickness and poloidal coverage of the breeder dropped the TBR by 20\%. Introducing the 2 cm wide assembly gaps between the 16 blanket modules shows small effect on TBR, $<1 \%-3^{\text {rd }}$ step. The He-cooled ferritic steel (FS) structure is assigned to the IB and OB $3.8 \mathrm{~cm}$ thick first wall causing the TBR to drop by $9 \%-4^{\text {th }}$ step. Other side, back, top walls are added to the blanket perimeter reducing the TBR by $4 \%$
- $5^{\text {th }}$ step. The $1.5 \mathrm{~cm}$ thick He/FS cooling channels within the blanket were modeled to define the flow channels for the $\mathrm{LiPb}$ breeder, dropping the TBR by $6.5 \%-6^{\text {th }}$ step. All FS structures within the blanket are lined with $0.5 \mathrm{~cm}$ thick SiC flow-channel-inserts (FCI). Adding the FCI dropped the TBR by $5 \%-7^{\text {th }}$ step. Advanced physics require placing $\mathrm{W}$ stabilizing shells between the OB blanket segments, dropping the TBR by $2.6 \%-8^{\text {th }}$ step. In the $9^{\text {th }}$ step, the $7 \mathrm{~m}^{2}$ OB penetrations were considered showing a small effect on TBR (1.5\%).

In summary, limiting blanket coverage radially and vertically has significant impact on TBR (20\%), adding the FS structure and FCI has the largest reduction in TBR (23\%), inclusion of stabilizing shells has 2.6\% impact on TBR, and adding penetrations and assembly gaps has smaller ( 2\%) but still notable impact on TBR.

Besides the great interest in understanding how the design elements impact the breeding in an integral fashion, operating with ${ }^{6} \mathrm{Li}$ enrichment $<90 \%$ is highly desirable to address this important question: How to deal with the shortage or surplus of tritium obtained as a consequence of the actual operational life of the ARIES power plant? The most attractive scheme for the LiPb breeder in particular is to increase/decrease the ${ }^{6} \mathrm{Li}$ enrichment online shortly after plant operation [5]. This helps mitigate concerns about the danger of placing the plant at risk due to tritium shortage as well as the problem of handling and safeguarding any surplus of tritium. For this reason, the IB blanket was thickened by $20 \mathrm{~cm}$ to achieve a TBR of 1.05 with an enrichment of $70 \%-10^{\text {th }}$ step. The final DCLL blanket is shown isometrically in Figure 3.

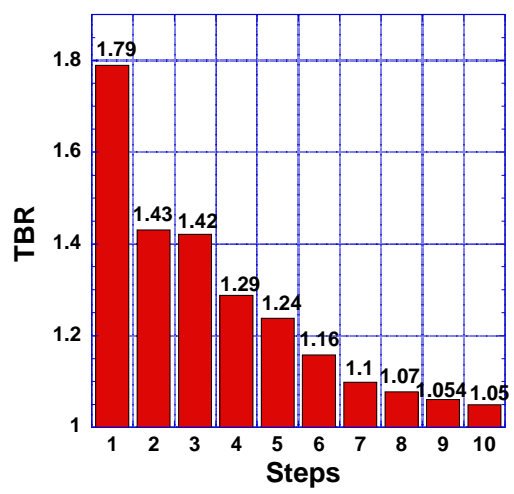

Figure 2. Bar chart showing reduction in TBR upon including blanket internals and externals.

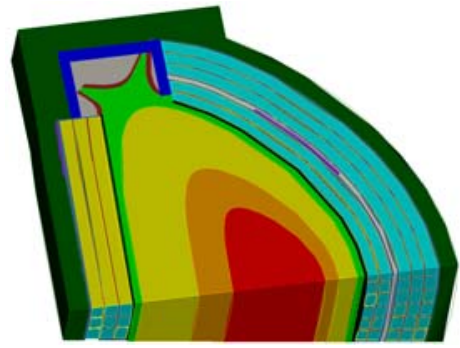

Figure 3. Isometric of ARIES-ACT DCLL blanket showing cross section of $0.65 \mathrm{~m}$ thick IB and $1 \mathrm{~m}$ thick OB blankets at the midplane. 


\section{Shielding considerations}

The transition between fusion concepts (tokamak, stellarator, and spherical torus) always involves a significant change in the shielding strategy, but with a common focus on compactness (for economic competiveness) and smart selection of shielding materials to meet the safety and environmental constraints. In the depth of the power core behind the blanket and divertor, where the neutron flux is too low for efficient production of tritium, there is still significant flux to damage the outer components. All in-vessel components (blanket, vacuum vessel, etc.) should provide a shielding function and help protect the externals. Nevertheless, large penetrations for plasma control and assembly gaps between blanket and shield modules jeopardize the shielding effectiveness of these components. We developed novel ideas [6,7] to alleviate the streaming problem and effectively protect the IB vacuum vessel and magnet in particular.

Well-optimized shielding components not only define the operational space of the machine, but ultimately minimize the burden of unnecessary radioactive materials generated by a non-optimized radial build. Outlined below is a brief summary of the main shielding issues facing selected fusion concepts.

\subsection{Tokamak shielding}

The shielding effort focuses on the IB area where a better shielding performance makes a notable difference to the overall tokamak size and economic enhancements are gained with high-performance shield [8,9]. Figure 4 displays the IB radial build for the ongoing ARIES-ACT study [1]. When combined with water, WC offers superior shielding capacity for the low-temperature (LT) shield. A tradeoff analysis of water and WC filler defined the optimal composition and dimension of the LT shield.

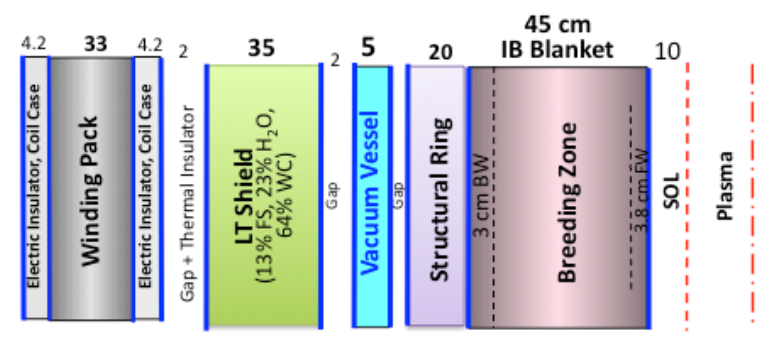

Figure 4. ARIES-ACT inboard radial build.

\subsection{Stellarator shielding}

The compact stellarator study (ARIES-CS [10]) aimed at reducing the minimum plasma to coil distance $\left(\Delta_{\min }\right)$ to achieve high compactness. Being the most influential parameter for the stellarator's size and cost, $\Delta_{\min }$ optimization was crucial to the overall design. In this study, the three design disciplines (physics, shielding, and economics) proceeded interactively while the systems code determined the optimal design parameters. An innovative approach was developed to downsize the blanket at $\Delta_{\min }$ and utilize a more efficient WC shield to adequately protect the magnet at these critical locations that cover $\sim 25 \%$ of the first wall (FW) area. Elsewhere, a full blanket was deployed, as shown in Figure 5, to provide the necessary breeding. This novel shielding approach developed specifically for $\Delta_{\min }$ helped reduce the radial standoff by $\sim 28 \%$, the major radius by $\sim 30 \%$, and the cost of electricity by $\sim 12 \%$ relative to a case with full blanket installed everywhere.

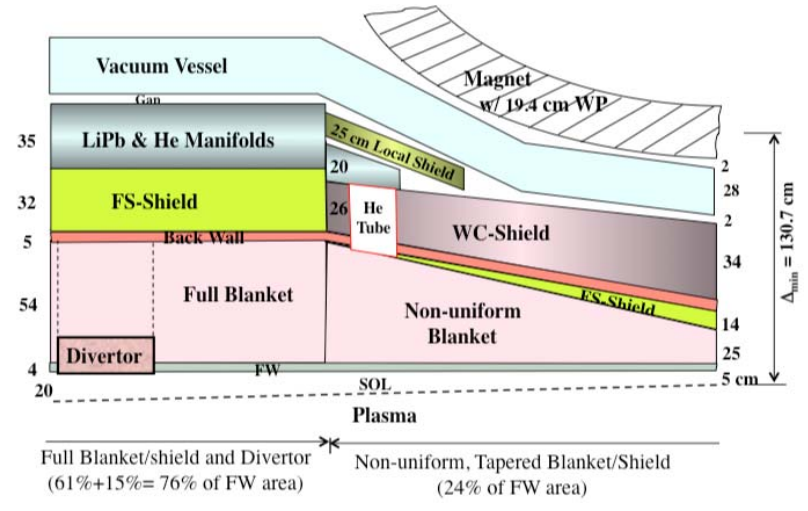

Figure 5. ARIES-CS cross section at $\Delta_{\min }$.

\subsection{Spherical torus shielding}

The spherical torus (ST) has a unique configuration with $\mathrm{Cu}$ center-post (CP) at the center of the machine. The protection of the $\mathrm{CP}$ against radiation and the influence of the IB shield on the performance of the machine are critical issues that received special attention during the ARIES-ST study [11]. The main concern is that a bare 900 ton CP will not survive the intense radiation and will require frequent replacement every two months to avoid generating high-level waste. Selecting the optimum shielding parameters was a complex task that involved trade-offs between several competing factors. An effort to only reduce the CP Joule losses and neglect the benefits of the IB shield led to non-optimum ST designs. The significance of the $20 \mathrm{~cm}$ thick FS/He IB shield is in its positive impact on the OB breeding, overall power balance, economics, and environment of ARIES-ST [11].

\section{Activation considerations}

The activation of fusion components impacts the safety of the machine, the environment, and the health and safety of the workers and general public. Since the early 1970s, fusion researchers had the advantage of selecting materials based on low neutron-induced activation that reduces the amount of radioactivity generated over decades of plant operation. As such, all ARIES designs incorporate low-activation materials, such as ferritic steels, vanadium alloys, SiC/SiC composites, and $\mathrm{W}$ alloys. The environmental issue received special attention, as fusion tends to generate a 
sizable amount of mildly radioactive materials, compared to fission. We developed an integrated management strategy that takes into account the environmental, political, and present reality in the US. The new strategy calls for recycling and clearing the fusion radioactive materials, and avoiding the geological disposal option as much as practically possible [12].

Past ARIES and international studies [12,13] indicated all in-vessel components can potentially be handled and eventually be recycled using conventional and advanced remote handling equipment. Storing the various components for several years helps reduce the dose by a few orders of magnitude before recycling.

The clearance index for all internal components (blanket, shield, and vacuum vessel) exceeds unity by a wide margin even after an extended period of $100 \mathrm{y}$. This means these components cannot be cleared, but should be recycled (or disposed of in repositories as low-level waste). The bulky biological shield and some magnet constituents qualify for clearance, however.

Overall, $70-80 \%$ of all fusion radioactive materials, including the bioshield, can be cleared within $100 \mathrm{y}$ after decommissioning; the remaining $20-30 \%$ of materials are recyclable. The recycling/clearance approach solves fusion's large radwaste problem, frees ample space in repositories for non-fusion non-recyclable radwaste, preserves natural resources, minimizes the radwaste burden for future generations, and promotes fusion as an energy source with minimal environmental impact.

\section{Conclusion}

This paper outlines the role of nuclear assessment in tackling the design issues and demonstrates several important nuclear-related requirements established for the ARIES project. Examples include estimating the TBR with high fidelity using state-of-the-art computational tools, the online adjustment of breeding for liquid breeders in particular, the extensive optimization of the radial standoff that impacts the machine size and cost the most, and the development of more environmentally attractive scenarios, such as recycling and clearance, to replace the geological disposal option. The collective impact of such requirements has done much to shape the design development of various ARIES concepts in terms of the overall machine layout, size, economics, and environment.

\section{Acknowledgement}

This work was performed under the auspices of the US Department of Energy under contract \#DE-FG02-98ER 54462.

\section{References}

[1] The ARIES Project: http://aries.ucsd.edu/ARIES/.

[2] DAGMC Users Guide, University of Wisconsin
-Madison Fusion Technology Institute, (2008). Available at:

http://cnerg.engr.wisc.edu/cgi-bin/index.cgi/wiki?p $=$ DagmcUsersGuide.

[3] X-5 Monte Carlo Team, MCNP-A General Monte Carlo N-particle Transport Code, Version 5, Volume I: Overview and Theory, LA-UR-03-1987; Volume II: User's Guide, LA-CP-03-0245; Volume III: Developer's Guide, LA-CP-03-0284, Los Alamos National Laboratory, (October 2005).

[4] L. El-Guebaly, A. Jaber and S. Malang, State-of-the-art 3-D assessment of elements degrading the TBR of the ARIES DCLL blanket, $J$. Fusion Science and Technology 61 (4) (2012), pp. 321-331.

[5] L. El-Guebaly and S. Malang, Toward the ultimate goal of tritium self-sufficiency: technical issues and requirements imposed on ARIES advanced fusion power plants, J. Fusion Engineering and Design 84 (2009), pp. 2072-2083.

[6] T. Bohm and L. El-Guebaly, Novel solution for the problem of neutron streaming through inboard assembly gaps of ARIES tokamak power plants, $J$. Fusion Science and Technology 60 (1) (2011), pp. 278-282.

[7] A. Ibrahim, D.L. Henderson, L.A. El-Guebaly, P.P.H. Wilson and M.E. Sawan, Three dimensional analysis of radiation streaming through ARIES-CS He-access pipes, J. Fusion Science and Technology 56 (2) (2009), pp. 726-730.

[8] L.A. El-Guebaly, Overview of ARIES-RS neutronics and radiation shielding: key issues and main conclusions, J. Fusion Engineering and Design 38 (1997), pp. 139-158.

[9] L.A. El-Guebaly, Nuclear performance assessment of ARIES-AT, J. Fusion Engineering and Design 80 (2006), pp. 99-110.

[10]L. El-Guebaly, P. Wilson, D. Henderson, M. Sawan, G. Sviatoslavsky, T. Tautges, R. Slaybaugh, B. Kiedrowski, A. Ibrahim, C. Martin, R. Raffray, S. Malang. J. Lyon, L.P. Ku, X. Wang, L. Bromberg, B. Merrill, L. Waganer and F. Najmabadi, Designing ARIES-CS compact radial build and nuclear system: neutronics, shielding, and activation, J. Fusion Science and Technology 54 (3) (2008), pp. 747-770.

[11]L.A. El-Guebaly, ARIES-ST nuclear analysis and shield design, J. Fusion Engineering and Design 65 (2003), pp. 263-284.

[12]L. El-Guebaly, V. Massaut, K. Tobita and L. Cadwallader, Goals, challenges, and successes of managing fusion active materials, J. Fusion Engineering and Design 83, Issues 7-9 (2008), pp. 928-935.

[13]M. Zucchetti, L. Di Pace, L. El-Guebaly, B.N. Kolbasov, V. Massaut, R. Pampin, and P. Wilson, The back end of the fusion materials cycle, $J$. Fusion Science and Technology 52 (2) (2009), pp. 109-139. 